\title{
Hotspots Evolution and Frontier Analysis of Lean Construction Research - Integrated Scientometric Analysis using the Web of Science and Scopus Databases
}

\begin{abstract}
To develop a lean and green construction industry, Lean Construction (LC) is proposed as a new construction production method to improve the efficient use of resources and the value of construction supply chains, which has received increasing research concerns from scholars and practitioners. Based on related articles covered by the Web of Science and Scopus databases between 1995 and 2014, this study conducts a scientometric analysis. The analysis identifies four core topics in existing research, including: Last Planner System (LPS); production control theory; improvement and evaluation of productivity; and principle of value. Three major directions of LC research: greening LC; Building Information Modeling (BIM) based LC; and lean safety management, are also proposed. Lastly, several recommendations for future LC research and practice are provided in the literature review.
\end{abstract}

Keywords: Lean Construction, green industry, efficient use

\section{Introduction}

By 2025 the construction industry is expected to account for $13.5 \%$ of the world's economic output. Infrastructure renewal in developed countries and urban growth in developing countries (Global Construction Perspectives \& Oxford Economics, 2013) partially explains the reasons of 2025 prediction (TFV). The construction business is a high energy consuming industry. Dealing with the relation-

Manuscript received March 1, 2015; accepted May 30, 2015

Qing-hua He, Ge Wang $(\bowtie)$

Research Institute of Complex Engineering \& Management, School of Economics and Management, Tongji University, Shanghai 200092, China

Email: 2014_wangge@tongji.edu.cn ship between resources and environment during the process of rapid development has become a shared challenge around the world. Therefore, establishment of a green production pattern that comes with industry upgrade has become a focus of research in the field of construction management.

As a production philosophy, lean, originated with the "Toyota Production System" in the 1970s. Although lean theory stemmed from Japan, it quickly caused wide concern among Western scholars. Womack, Jones, and Roos (1990) put forward the "Lean Production" pattern, and discussed the differences between two main patterns of manufacturing, mass production, and lean production. Koskela (1992) pointed out that it is necessary to apply new production philosophies to construction, first proposing the concept of "Lean Construction". "Lean Construction" (LC) is a production management-based approach aiming at meeting owner's needs. LC extends the objectives of a lean production system - value maximization and waste minimization to specific techniques and applies them in a new project delivery process (Howell, 1999).

With the establishment of International Group of Lean Construction (IGLC) and Lean Construction Institute (LCI), scholars from across six continents have conducted much of LC-related research. Britain, Ireland, Denmark, Germany, Norway, Australia, Finland, Brazil and Chile have established the branches of LCI. Extension of the LC concept is expanding, including Building Information Modeling (BIM), Integrated Project Delivery (IPD), Target Value Design (TVD), Last Planner System (LPS) and other methods as well as Transformation-Flow-Value (TFV), Kaizen, sustainable development and other philosophies (Gao \& Low, 2014).

\section{Data sources and research method}

CiteSpace is designed as a tool for progressive knowledge domain visualization (Chen, 2004). It provides various 
functions to facilitate the understanding and interpretation of network structures and historical patterns, including

*identifying the fast-growth topical areas;

* finding citation hotspots in the land of publications;

*dividing a network into clusters;

*automatic labeling of clusters with terms from citing articles;

* geospatial patterns of collaboration, and unique areas of international collaboration (Chen, 2006).

CiteSpace III was used to analyze the knowledge map in the field of LC. First, records of 621 articles were retrieved based on the following search strategy:

"Terms $=$ LC; time span = from1995 to 2014; databases $=$ Web of Science or Scopus". By way of development history and hotspots, the evolution of LC was systematically analyzed from the perspective of time and spatial distribution as well as research content, as shown in Figure 1.

The number of published articles from Web of Science and Scopus suggests that LC research has experienced rapid development in 20 years, as shown in Figure 2. The period of 1995 to 2004 could be labeled as the "formation stage" of LC research due to a lack of published articles. The number of articles published increased significantly from 2005, peaking in 2012. The period after 2004 could be regarded as development stage of LC research.

\section{Data analysis and results}

\subsection{Spatial distribution of LC research}

The Pathfinder pruning algorithm was used for country cooccurrence network analysis. The time span was set between 1995 and 2014, taking two years as a time slice. As shown in Figure 3, each node represents a country, and the thickness of the rings is proportional to the number of published articles. Centrality is used to indicate the centrality of a node, which reflects the connection and intermediation functions of the nodes in different clustering networks. Nodes whose centrality is greater than or equal to 0.1 are often defined as key nodes in CiteSpace (Hou \& Liu, 2009).

In the Web of Science and Scopus databases, authors of LC-related articles come from 38 countries and regions in Asia, Europe, North America, South America, Africa and Oceania. LC has gradually become an international research area, which develops a "one superpower and multi powers' status. One superpower is the United States, while multi powers respectively represent Britain, Brazil, and China.

The United States, Britain, China, Brazil and Chile ranked in the top five according to the number of published articles. The centrality of United States is the highest and it

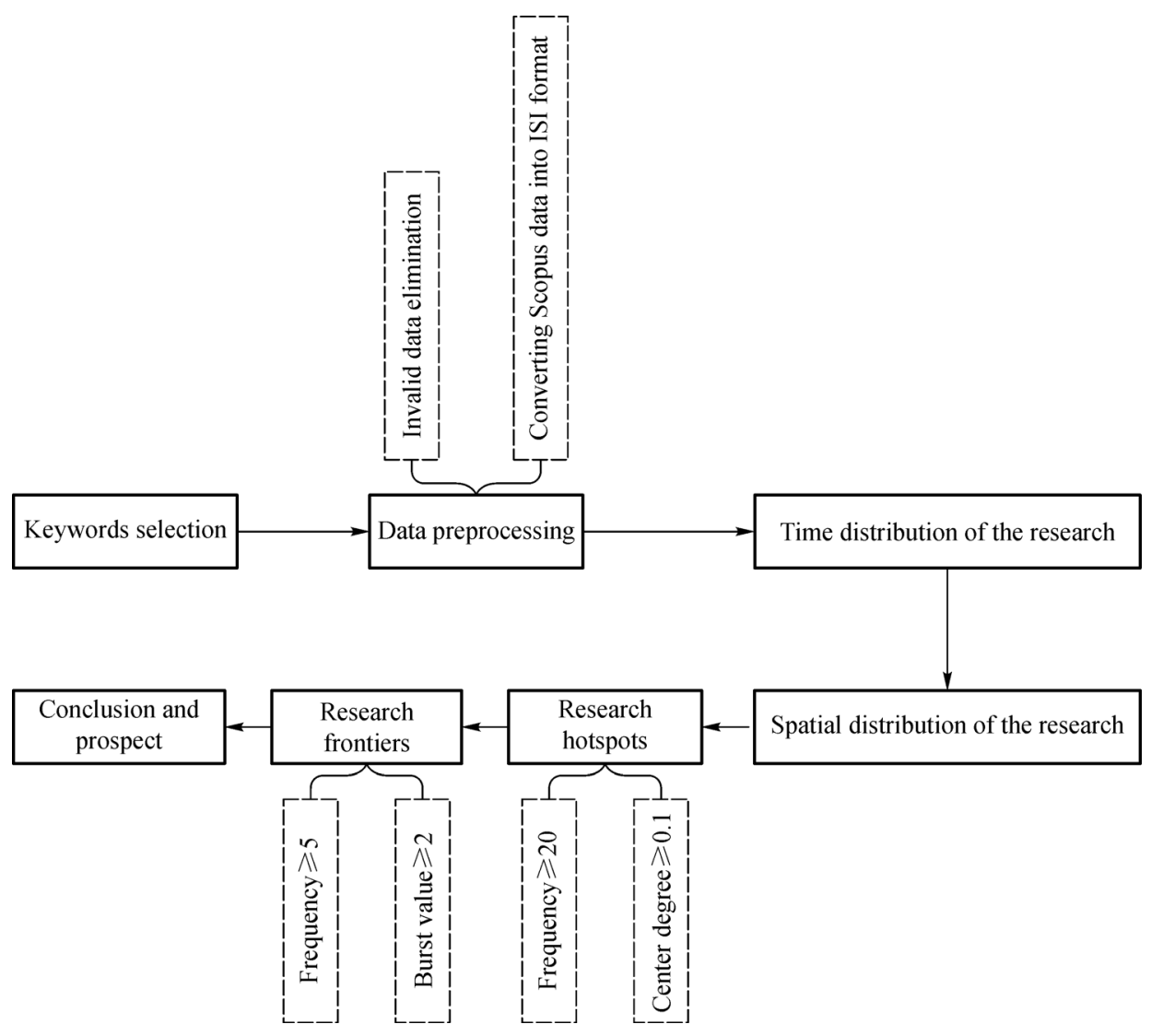

Figure 1. Flow chart of data processing and analysis. 


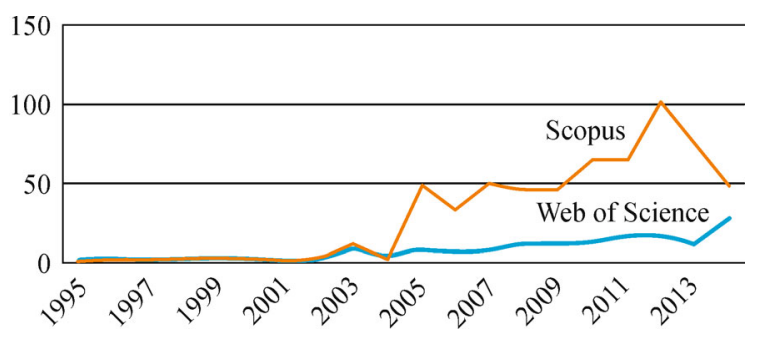

Figure 2. LC research development 1995-2014.

has a close contact and cooperation with Britain, Germany, Finland, Republic of Korea, Brazil and New Zealand. As a representative of North America, the development of LC is relatively mature in the United States. For instance, both Sutter Health Center and Whiting Refinery Project are very successful cases that implement LC (Forbes \& Ahmed, 2010). In Europe, LC research has centered upon Britain, Germany, Finland, Norway and Sweden. Britain is second only to the United States in terms of centrality and the number of published articles. Several colleges and universities in Britain have LC research institutions such as Lean Construction Group at Loughborough University, University of Huddersfield - Innovative Design Laboratory, Salford Centre for Research and Innovation. China is ranked third in the number of published articles and far outpaces Republic of Korea, Japan and other Asian countries. China lacks contact with American and European countries. International cooperation of LC research in China still needs to be improved. In South
America, LC research centered upon Brazil and Chile. Both of these two developing countries have wide construction markets and established cooperative relationships with the United States, New Zealand and Germany. There is a broad prospect for LC research in Brazil and Chile.

\subsection{Hotspots of LC research}

As the core and essence of articles, keywords could highly summarize research directions and topics. A significant function of CiteSpace is to probe the research hotspots in related fields by analyzing keyword frequencies. Pathfinder pruning algorithm was used for keywords co-occurrence network analysis. Time span is set between 2010 and 2014, and time slice is 1 year, as shown in Figure 4.

The number of keywords whose occurrence frequency is greater than or equal to 5,10 and 20 respectively is listed as follows: 60, 41 and 18. Through keywords excluding, such as basic or characteristic words in LC-related articles (LC, Construction Industry, Project Management), hot spots of LC research are determined further, as shown in Table 1.

Since LPS was formally proposed by Ballard in 1994, it has received increasing attention. The "Last Planner" is the person, or group, responsible for production unit control, that is, the completion of individual assignments at the operational level (Ballard, 1994). In essence, the LPS has five main integrated elements: master planning, phase planning, look ahead planning, weekly work planning as well as progress tracking and feedback (Ballard, 2000). In nearly five years, LPS-related research could be summarized as the following aspects: operational effect evaluation
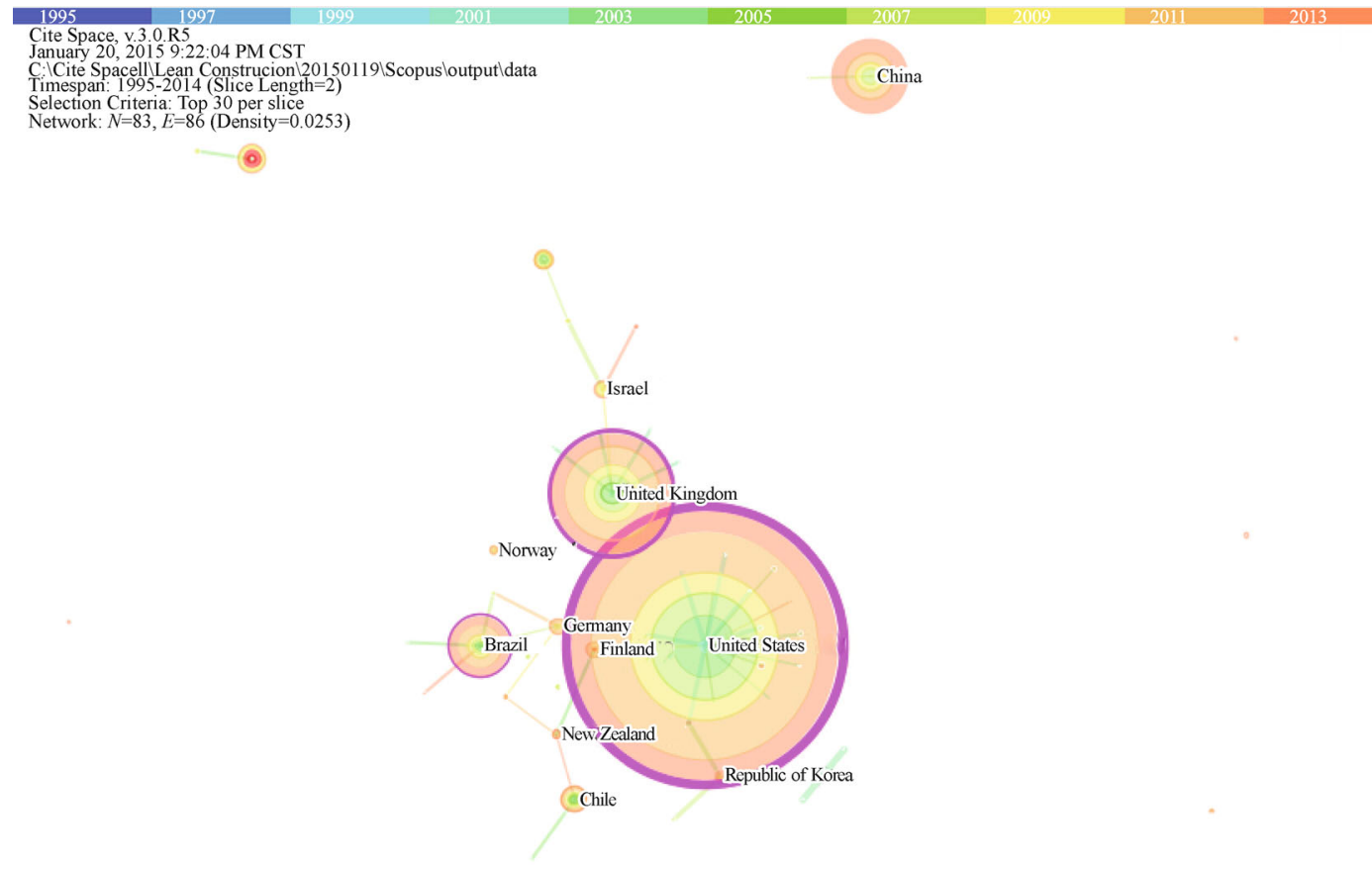

Figure 3. Country co-occurrence network of LC research. 


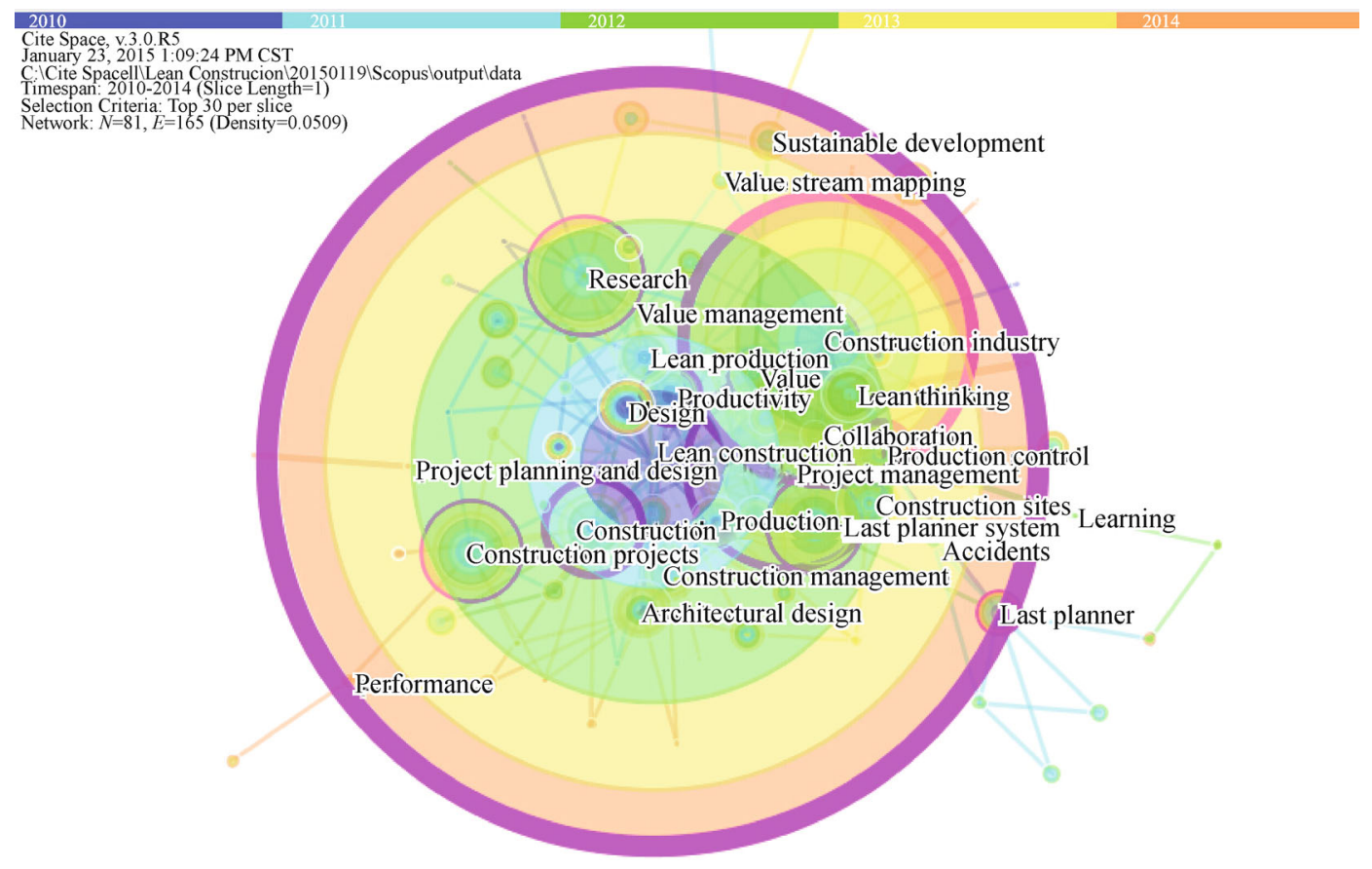

Figure 4. Keywords co-occurrence network of LC research.

Table 1

Hotspots of LC Research from 2010 to 2014

\begin{tabular}{lccc}
\hline Number & Keywords & Frequency & Centrality \\
\hline 1 & Last planner system & 38 & 0.15 \\
2 & Production control & 26 & 0.23 \\
3 & Productivity & 24 & 0.14 \\
4 & Value & 21 & 0.18 \\
\hline
\end{tabular}

of LPS, such as PPC (Percent Plan Complete) and EVM (Earned Value Method); application of LPS in different countries, such as Finland, Nigeria, Brazil, China, New Zealand and Mexico; combination of LPS and other techniques or tools, such as Location-Based Management System (LBMS), BIM, Design Structure Matrix (DSM).

TFV is the basic theory of LC, which emphasizes the life cycle control of construction project by three dimensions: conversion, process and value. As a keyword with the highest centrality, "Production Control" is the intermediate node of LPS, JIT (Just In Time), 5S, Kaizen, Kanban, which reflects its basic position in LC research.

Productivity is a significant indicator for measuring lean performance. How to use lean tools to improve and evaluate the productivity of construction projects has been a hotspot in LC research: 1) Ikuma, Nahmens, and James (2011) combined lean production strategies and traditional safety-analysis tools to address two biggest challenges in the construction industry, low productivity and high injury rates; and, 2) Koskenvesa and Koskela (2011) compared the original prescription of the traditional conceptual model of productivity and performance with TFV-theory.

Value was defined by Womack and Jones (1996) as one of the five criteria of "lean management". The core concept of LC is to maximise value and minimise waste. Value, as a concept, has rich connotations: 1) Erikshammar, Bjornfot and Gardelli (2010) illustrated how utility theory can be used to provide a consensus on value that is acceptable; 2) Maia, Lima and Neto (2011) developed a solid and coherent theoretical background for value through a systemic approach in several areas of knowledge, including sustainability and ethical responsibility, etc. Value-related keywords in the field of LC include: Value Chain, Value Added, Value Stream Mapping (VSM), Value Based Management and TVD.

\subsection{Frontiers of LC research}

Frequency changes over time can be understood through the technique of burst detection - a function in CiteSpace. Burst detection reveals unusually large changes in the frequency of a datum over time (Pollack \& Adler, 2015). 
Table 2 is a result of the burst analysis of keywords from 2010 to 2014 , showing the top three bursting keywords category, as sorted by the content correlation.

In the past 5 years, the relationship between LC and sustainability has been the focus of attention. LC research in relation to sustainability includes the following aspects:

1) The impact of application of lean tools on sustainability: Ahuja (2012) examined how current LC tools and methods impact the construction and operation of sustainable facilities. Ogunbiyi, Oladapo, and Goulding (2013) identified several areas of linkage between lean and sustainability and raising awareness of the benefits that can be derived from the implementation of LC in sustainable construction.

2) The impact of lean and sustainability on project performance: Valente, Mourão, and Neto (2013) explained how lean and green can complement and help each other in achieving strategic, tactical and operational objectives of a company through a case study.

3) Application of lean tools in environmental performance evaluation: Rosenbaum, Toledo, and González (2014) applied VSM as a green-lean approach in the construction of a hospital to confirm its ability to detect the sources of environmental and production waste, as well as quantify them, and suggest reduction strategies.

BIM is an important tool for LC. LC research related to BIM includes the following aspects. 1) Relationship between LC and BIM: Sacks, Dave, Koskela, and Owen (2009) conducted a conceptual analysis of the interaction of LC and BIM for improving construction; Clemente and Cachadinha (2013) proposed using a combined approach of BIM tools and lean techniques to coordinate MEP works and achieve significant reductions of non-added value activities and duration as well as aligning stakeholder interests toward a common objective in view of meeting the overall project schedule. 2) Application and development of BIM: Dave, Boddy, and Koskela (2013) applied VisiLean, a research software which provides integration between the lean workflow and the BIM model, on an infrastructure project and the associated challenges were identified pertaining to the level of detail, and the parametric nature of the existing BIM during the pilot implementation. 3) The impact of BIM on project performance: Dossick, Azari, Kim, and El-Anwar (2013) found that lean and BIM tools reinforced the project team's integration and facilitated better results in terms of design and construction products through a healthcare case study.

Safety has always been important in the construction industry. LC research related to safety includes the following aspects. 1) The impact of LC on safety management: Antillon, Alarcon, Hallowell, and Molenaar (2011) developed an interaction matrix to validate the synthesis between lean construction and safety management practices; Forman (2013) saw LC and Health and Safety (H\&S) work as two different societal change programmes and found that the stabilization of new routines for coupling LC and $\mathrm{H} \& \mathrm{~S}$ were dependent on the relationship between the functional departments at the company and the construction project. 2) Application of lean tools in safety management: Leino, Elfving, and Ballard (2010) introduced lean tools to provide a platform for risk assessment, worker involvement, organisational learning and securing that there are no safety constraints in place.

\section{Conclusions and prospects}

In the past, development was characterized by extensive growth and high energy-consumption; construction enterprises usually rely on cheap labor and raw materials to control cost. However, with resource scarcities, environmental pollution and other issues becoming increasingly serious, the promotion of LC appears imminent and will be one of the key factors that affect the core competitiveness of construction industry.

At different times, stages and situations, LC hotspots constantly change according to the different requirements of external practice. Early LC research tended to migrate toward the applications of lean production technique. With the development of economic globalization and the rise of interdisciplinary research, LC integrated with information management, complexity science and other fields, showing an international and diversified development trend.

At the same time, the temporal and spatial distribution of related articles indicates that LC research is developing rapidly since 2004 and expanded from the United States and Britain to developing countries, such as Brazil, Chile,

Table 2

\begin{tabular}{|c|c|c|c|c|c|}
\hline Number & Category & Keywords & Burst & Frequency & Centrality \\
\hline 1 & Sustainability & Sustainable development & 2.99 & 17 & 0.06 \\
\hline 2 & & Sustainability & 2.94 & 16 & 0 \\
\hline 3 & BIM & Building information modeling/BIM & 2.98 & 7 & 0.01 \\
\hline 4 & Safety & Accident prevention & 2.72 & 9 & 0 \\
\hline 5 & & Safety & 2.72 & 9 & 0 \\
\hline
\end{tabular}


and China. Traditional theory and tools of LC, such as LPS, production control theory, improvement and evaluation of productivity, principle of value, have been the focus of scholars. Along with the development of information technology and low-carbon transformation of construction industry, greening LC, BIM based LC, and lean safety management have gradually become the research frontiers. Although a lot of valuable achievements in the field of LC have been made, the following issues need to be further improved and expanded.

(1) Theoretical principle mining of LC.

TFV has developed a new approach for LC research, but the overall research perspective that focuses on the conversion, process and value dimensions is relatively feeble. Organization is the decisive factor for the realization of project objectives. The smooth implementation of LC is contingent on the enterprise organization and support of the project. Therefore, it's helpful to enrich the theory system of LC from the perspective of organizational behavior, organizational ecology and resource dependence theory, etc.

(2) Research scope expansion of LC.

LC plays an important role in cost control, quality control, schedule control and safety management. With the rise of IPD and BIM, traditional contract management methods and information management tools are also undergoing changes. However, at present the research of risk management in LC has not evolved. The implementation of LC also means technology and management changes for the project organization. It's necessary to control risk in the change process, and therefore how to eliminate the resistance to change, create a favorable environment for the organization and reduce the risk of transformation is still to be dealt with.

(3) Development of LC tools.

The sustainable development of LC is inseparable from the progress of more new methods and tools. How to effectively integrate the LPS, BIM, VSM and develop professional softwares that have the characteristics of high reliability, easy operation and friendly interface is still in need of further exploration.

\section{References}

Ahuja, R. (2012). Sustainable construction: is lean green? ICSDEC 2012. Developing the Frontier of Sustainable Design, Engineering, and Construction, 903-911

Antillon, E.I., Alarcon, L.F., Hallowell, M.R., \& Molenaar, K.R. (2011). A research synthesis on the interface between lean construction and safety management. Proceedings of the 19th Annual Conference of the International Group for Lean Construction

Ballard, G. (1994). The last planner. Monterey, California: Northern California Construction Institute

Ballard, H.G. (2000). The last planner system of production control. (Doctoral dissertation). Birmingham: The University of Birmingham.
Chen, C. (2004). Searching for intellectual turning points: progressive knowledge domain visualization. Proceedings of the National Academy of Sciences of the United States of America (PNAS), 101 (Suppl. 1), 5303-5310

Chen, C. (2006). CiteSpace II: Detecting and visualizing emerging trends and transient patterns in scientific literature. Journal of the American Society for Information Science and Technology, 57, 359-377

Clemente, J., \& Cachadinha, N. (2013). BIM-Lean synergies in the management on MEP works in public facilities of intensive use - a case study. Proceedings of the 21th Annual Conference of the International Group for Lean Construction, 751-760

Dave, B., Boddy, S., \& Koskela, L. (2013). Challenges and opportunities in implementing lean and BIM on an infrastructure project. Paper presented at the 21th Annual Conference of the International Group for Lean Construction

Dossick, C., Azari, R., Kim, Y., \& El-Anwar, O. (2013). IPD in practice: sustaining collaboration in healthcare design and construction. AEI 2013: Building Solutions for Architectural Engineering, 377-386

Erikshammar, J.J., Bjornfot, A., \& Gardelli, V. (2010). The ambiguity of value. Paper presented at the 18th Annual Conference of the International Group for Lean Construction

Forbes, L.H., \& Ahmed, S.M. (2010). Modern Construction: Lean Project Delivery and Integrated Practices. Boca Raton: CRC Press

Forman, M. (2013). Inertia and change: lean construction and health and safety work on construction sites. Construction Management and Economics, 31, 647-660

Gao, S., \& Low, S.P. (2014). Lean Construction Management: the Toyota Way. Singapore: Springer

Global Construction Perspectives \& Oxford Economics. (2013). Global construction 2025: a global forecast for the construction industry to 2025. Global Construction Perspectives Ltd

Hou, J., \& Liu, Z. (2009). Visualizing the research fronts and evolution of nanotechnology. Science of Science and Management of $S . \&$ T., 30 (5), 23-30

Howell, G.A. (1999). What is lean construction? Proceedings of 7th Annual Conference of the International Group of Lean Construction. University Of California, Berkeley, CA, USA

Ikuma, L.H., Nahmens, I., \& James, J. (2011). Use of safety and lean integrated kaizen to improve performance in modular homebuilding. Journal of Construction Engineering and Management, 137(7), 551560

Koskela, L. (1992). Application of the new production philosophy to construction (No.72). Stanford, CA: Stanford University

Koskenvesa, A., \& Koskela, L. (2011). Evaluating site performance through the TFV-Theory. Proceedings of the 19th Annual Conference of the International Group for Lean Construction

Leino, A., Elfving, J., \& Ballard, G. (2010). Accident rate down from 57 to 9 in five years. Paper presented at the 18th Annual Conference of the International Group for Lean Construction

Maia, S., Lima, M., \& Neto, J.B. (2011). A systemic approach to the concept of value and its effects on Lean Construction. Paper presented at the 19th Annual Conference of the International Group for Lean Construction

Ogunbiyi, O., Oladapo, A., \& Goulding, J. (2014). An empirical study of the impact of lean construction techniques on sustainable construction in the UK. Construction Innovation, 14(1), 88-107 
Pollack, J., \& Adler, D. (2015). Emergent trends and passing fads in project management research: a scientometric analysis of changes in the field. International Journal of Project Management, 33(1), 236248

Rosenbaum, S., Toledo, M., \& González, V. (2014). Improving environmental and production performance in construction projects using Value-Stream Mapping: case study. Journal of Construction Engineering and Management, 140(2), 1-11

Sacks, R., Dave, B.A., Koskela, L., \& Owen, R. (2009). Analysis framework for the interaction between lean construction and building information modelling. Proceedings of the 17th Annual Conference of the International Group for Lean Construction

Valente, C.P., Mourão, C.A.M.A., \& Neto, J.B. (2013). Lean and green: how both philosophies can interact on strategic, tactical and operational levels of a company. Proceedings of the 21th Annual Conference of the International Group for Lean Construction

Womack, J.P., \& Jones, D.T. (1996). Lean Thinking: Banish Waste and Create Wealth in Your Corporation. New York: Simon \& Shuster

Womack, J.P., Jones, D.T., \& Roos, D. (1990). The Machine that changed the world: the story of lean production: How Japan's secret weapon in the global auto wars will revolutionize western industry. New York, NY: Rawson Associates 